Primljen / Received: 15.12.2012. Ispravljen / Corrected: 18.1.2013.

Prihvaćen / Accepted: 21.2.2013. Dostupno online / Available online: 10.5.2013.

\section{Target acceleration in multimodal pushover method for R/C frames}

Preliminary note

\author{
Ivan Balić, Ante Mihanović, Boris Trogrlić
}

\section{Target acceleration in multimodal pushover method for R/C frames}

The procedure of searching the target ground acceleration as a measure of the lowest seismic resistance is presented in the paper. This objective is achieved by the multimodal pushover analysis based on the envelope principle. The pushover method founded on the linear combination of modes (L), and on mode combinations as a square root of the sum of the squares (SRSS), is presented. Examples of 5-storey and 9-storey R/C frames point to a highly significant influence of higher modes. The failure ground acceleration in multimodal pushover analysis is significantly lower, and even several times lower, compared to the single mode acceleration.

Key words:

pushover method, combining of modes, R/C frame, target acceleration, general failure force vector

Ivan Balić, Ante Mihanović, Boris Trogrlié

Prethodno priopćenje

\section{Ciljano ubrzanje u višemodalnoj metodi naguravanja A/B okvira}

Prof. Ante Mihanović, PhD. CE

University of Split

Faculty of Civil Engineering, Arch. and Geodesy ante.mihanovic@gradst.hr

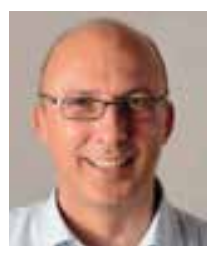

Prof. Boris Trogrlić, PhD. CE

University of Split

Faculty of Civil Engineering, Arch. and Geodesy boris.trogrlic@gradst.hr
U radu je prikazan postupak traženja ciljanog ubrzanja tla kao mjera najniže potresne otpornosti. Dobivanje ciljanog ubrzanja postiže se višemodalnim naguravanjem po načelu anvelope. Prikazano je naguravanje linearnom kombinacijom modova (L) i kombinacijom modova kao kvadratnog korijena iz sume kvadrata (SRSS). Na konkretnim primjerima 5-katnog i 9-katnog a/b okvira pokazuje se vrlo značajan utjecaj viših modova. Slomno ubrzanje tla u višemodalnom naguravanju značajno je manje, pa i višestruko manje od ubrzanja s jednim modom.

Ključne riječi:

metoda naguravanja, kombiniranje modova, a/b okvir, ciljano ubrzanje, opći slomni vektor

Vorherige Mitteilung

\section{Ivan Balić, Ante Mihanović, Boris Trogrlić}

\section{Zielbeschleunigung in der multimodalen Pushover Analyse für Stahlbetonrahmen}

In der vorliegenden Arbeit ist die Berechnung der Zielbodenbeschleunigung als Maß der niedrigsten Erdbebenbeständigkeit dargestellt. Die Zielbeschleunigung wird, auf dem Hüllkurven-Prinzip beruhend, durch eine multimodale Pushover Analyse ermittelt. Der Lastvektor ist sowohl als lineare Kombination (L) als auch in der Form der Quadratwurzel aus der Summe der Quadrate (SRSS) der Schwingformen beschrieben. Anschauliche Beispiele eines 5-stöckigen und eines 9-stöckigen Stahlbetonrahmens weisen auf den bedeutenden Einfluss höherer Schwingformen. Die kritische Bodenbeschleunigung bei der multimodalen Pushover Analyse ist bedeutend und sogar mehrfach kleiner als bei der ausschließlichen Berücksichtigung der ersten Eigenschwingung.

Schlüsselwörter:

Pushover Methode, Kombination von Schwingformen, Stahlbetonrahmen, Zielbeschleunigung, allgemeiner kritischer Lastvektor 


\section{Introduction}

The pushover method is an efficient procedure for the nonlinear analysis of earthquake resistance. In combination with the response spectrum for a single-degree-of-freedom system (SDOF), the method enables evaluation of the bearing capacity and strain of structures subjected to earthquake action. The method has been incorporated in various international codes for structural analysis, and is recommended by research institutions [1-3]. The development of the procedure adopted in EN 1998 was initiated three decades ago [4, 5], and various improvements and modifications, such as those proposed in papers [6, 7], are still being made [8]. The pushover method based on the distribution of accelerations according to the first mode, and constant distribution of accelerations along the height of the structure, is dominantly used in current practice. The influence of higher modes in nonlinear structural analysis based on pushover method has been analysed in many papers [9-15], and the authors agree that the influence of higher modes is considerable.

A multimodal pushover method, aimed at including higher modes so as to meet the envelope principle and define the least resistance, is presented in this paper. A concrete application of the method is possible for a specific elastic spectrum. The type 1 spectrum for the soil type A according to EN 1998 is used in examples presented in the paper. The bearing capacity curves are determined by pushover method separately for each mode, and are then converted into the ADRS format lacceleration displacement response spectrum) for the spectrum selected in advance. The form of modes a d period sizes are determined using the linear elastic model.

The method can be applied using the following set of steps:

- The procedure starts by selection of a concrete elastic spectrum.

- Then the hypothetic peak soil acceleration value is selected, usually the lowest one of all modes.

- An appropriate spectral acceleration and spectral load level is determined for each mode separately, based on the bearing capacity curve, taking into account the target displacement according to EN 1998. The form of load vector corresponds to the form of an appropriate mode.

- In addition, a general failure load vector is formed according to some possible load combinations for real modes. The following possible mode combinations are presented in the paper: linear (L) combination, and combination of the square root of the sum of the squares (SRSS).

- The bearing capacity, i.e. the design peak capacity, is determined for the load formed in this way, or general failure vector, by means of the non-linear analysis of the structure using the pushover method.

The task is considered solved when the load equality is obtained, within the accuracy set in advance, from the general failure vector and the design limit load for the assumed soil acceleration. The procedure conducted in several steps leads to a rapid solution for the selected different hypothetic acceleration and the corresponding vectors. The result obtained is the target acceleration which is the lowest acceleration that leads to the design limit state.
Based on the examples of linear $(\mathrm{L})$ combination of modes, and combination of the square root of the sum of the squares (SRSS), it can be concluded that the target acceleration is always lower that the limit acceleration for each mode regarded separately. This fact is the initial step in the method. The procedure presents properties of the envelope principle.

\section{Determination of target acceleration}

As previously indicated, the target acceleration seeking procedure starts by determination of the shape vector $\phi_{i}$ corresponding periods $T_{t^{\prime}}$ and participating masses $m_{e^{\prime}}$ based on the linearly elastic analysis. The load vector $F_{\text {i }}$ is determined separately for each $i$-th mode through the total action intensity factor $p$, as the product of the mass matrix $\mathbf{M}$ and the vector $\phi$

$\mathbf{F}_{i}=p_{i} \mathbf{M} \phi_{i}$

Load bearing capacity curves were calculated by the numerical model of stability and bearing capacity of spatial linear structures, taking into account material and geometric nonlinearities [16], with a monotonous increase of the load vector Fi. Failure-generating transverse forces in the crosssection were determined in this way at the basis of the calculation model separately for each mode.

When looking for the target acceleration, each attempt starts with an assumed target ground acceleration value $a_{g r}$. The ADRS curve is established for the assumed $a_{g r}$ elastic spectrum type (type 1 or type 2), type of soil (soil parameter $\mathrm{S}$ ), and damping correction factor ( $h=1$ for $z=5 \%$ viscous damping). Bearing capacity curves are converted into the ADRS format, separately for each mode.

The spectral acceleration $a_{s, i}$ is determined separately for each mode, according to EN 1998 and Annex B, so that the displacement at failure amounts to $150 \%$ of target displacement on the bearing capacity curve.

$d_{t}=\frac{2}{3} d_{u}$

The corresponding elastoplastic equivalent (bilinear forcedeformation diagram), i.e. the diagram in which the intercept of the period $T_{i}$ and the related target displacement $d_{t}$ falls on the ADRS curve of the assumed ground acceleration, must be determined. In other words, an equality between the ground acceleration $a_{g r, i}$ obtained in the i-nth attempt and the assumed ground acceleration $a_{g r}$ must be established, in order to define the spectral acceleration $a_{s, i}$

The procedure for determining the corresponding bilinear forcedeformation diagram is presented in Figure 1.

The selected bilinear force-deformation diagram is presented in Figures 1.a1) and 1.a2) for the case when the period is $T_{i} \geq T_{C}$. In Figure 1.a1), the selected diagram gives greater ordinates, and in Figure 1.a2) smaller ordinates, on the ADRS curve, when compared to the ADRS curve for the assumed ground acceleration $a_{g r^{\prime}}$ In Figure 1.a3), the selected diagram for the 

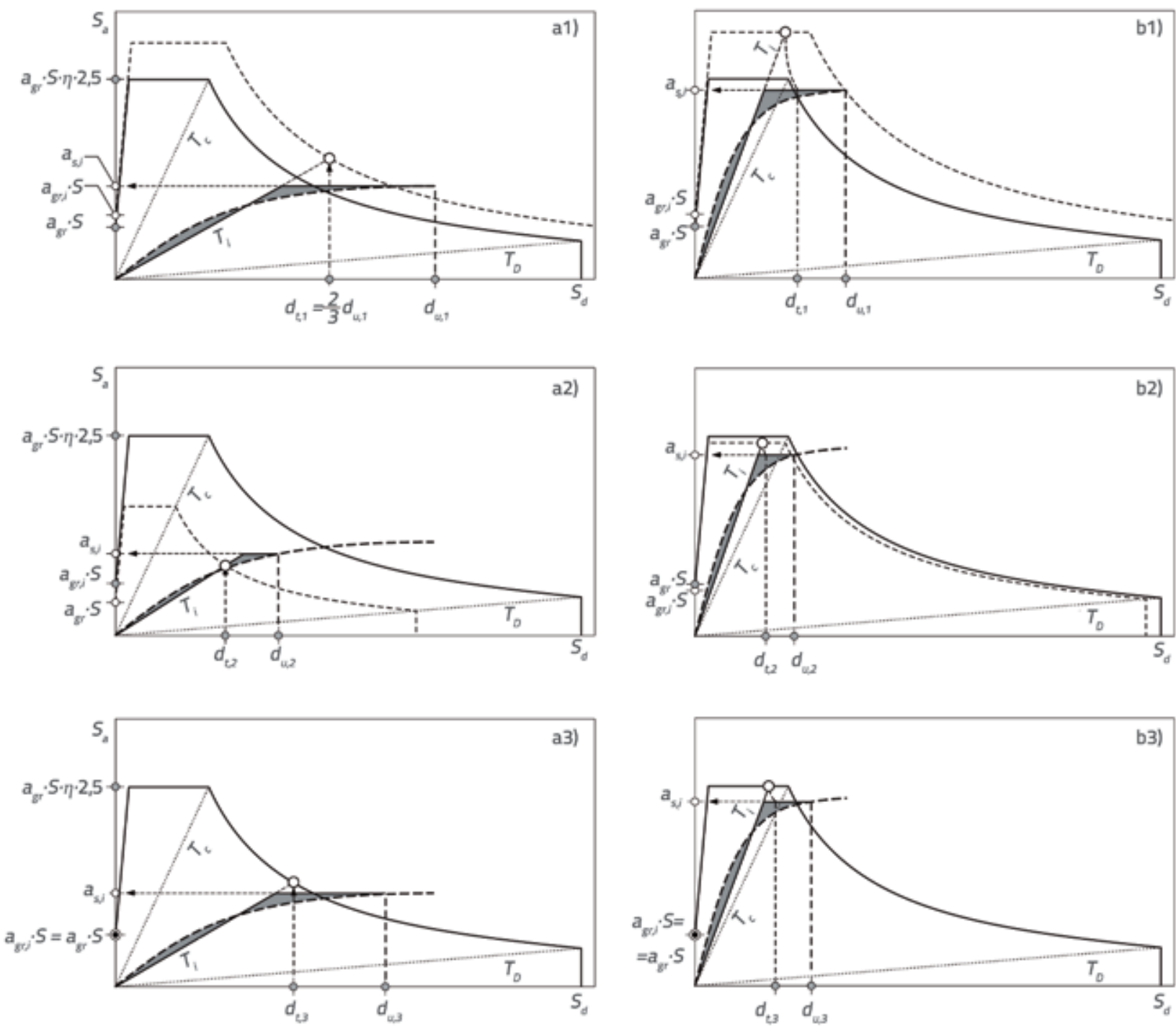

Figure 1. Determination of spectral acceleration $a_{s, i}$ a1)-a3) for $T_{i} \geq T_{c i} ;$ b1)-b3) for $T_{i}<T_{c}$

corresponding period $T_{i}$ and the related target displacement $d_{t}$ gives the intercept on the ADRS curve, which enables definition of the spectral acceleration $a_{s, i}$ A similar procedure is also conducted for the case when $T_{i}<T_{C}$ i.e. when the intercept is defined according to EN 1998 - Annex B.

Once the preceding step for each vector is determined, the parameter $\delta$, is defined as the ratio of the obtained spectral acceleration to the assumed ground acceleration.

$\delta_{i}=\frac{a_{s, i}}{a_{g r}}=\delta_{i}\left(a_{g r}\right)$

Furthermore, possible modal combinations are also defined. As already indicated, linear (L) combination, and combination of the square root of the sum of the squares (SRSS) is monitored. The target acceleration result is obtained via repeated attempts, by varying the assumed hypothetic acceleration as an input data.

\subsection{Target acceleration toward the linear (L) combination of modes}

The starting hypothetical limit load $\sum F_{i}$ for linear combination of modes depends on the initial acceleration selected, and can be presented as follows:

$\sum F_{i}=\sum \pm m_{e i} a_{s i}\left(a_{g r}\right) F_{f i} /\left|F_{f i}\right|$

where the sign \pm means more unfavourable effect on the typical cross-section. The typical cross-section for a RC frame example is presented via the sum of bending moments at the bottom of the lowest storey. The influence line for typical values can be used during selection of the sign.

The expression $F_{f i}$ represents the failure force for a particular eigenvector. It is assumed in numerical procedure that the load is applied in increments. As a result, the associated limit load was obtained, i.e. the total transverse force in the cross- 
section at the base of the calculation model $F_{L}$ for the entire system.

The adequacy of the initial assumption is shown by the ratio of the design limit load $F$ to the initial hypothetical load vector $\sum F$. As soon as their equality is obtained, within limits of the predefined design accuracy, it can be stated that the desired result has been obtained, which is the extreme limit acceleration, i.e. the target acceleration $a_{g r, t}$ corresponding to the smallest design ground acceleration.

\subsection{Target acceleration according to the root combination of modes (SRSS)}

The root combination, i.e. the method of the square root of the sum of the squares (SRSS) is the method that can be simplified as the sum of the first member and half-sum of all other members, in cases when the first addend is dominant. A half of the participating load of an individual higher mode is approximately equal to the total load belonging to the spectrum whose acceleration is $a_{g r} / 2$ [17], and so the corresponding combination can approximately be described with the following expression:

$$
\sum F_{i}= \pm m_{e 1} a_{\mathrm{s} 1}\left(a_{g r}\right) F_{\mathrm{f} 1} /\left|F_{\mathrm{f} 1}\right|+\sum_{i=2}^{n} \pm m_{e i} a_{s i}\left(a_{g r} / 2\right) F_{f i} /\left|F_{f i}\right|
$$

The remaining part of the procedure is analogous to that used for the linear combination.

\section{Examples}

Two examples of spatial RC frames, i.e. the 5-storey frame and 9-storey frame, are analysed in this section. The analysis is carried out with the following assumptions and limitations: (i) analysis of dynamic properties $\left(\phi_{i}, T_{i}, m_{e j}\right)$ is carried out on the linear model of the frame with floor slabs and the resulting elastic modulus $E_{d^{\prime}}$ (ii) the analysis does not include the accidental torsion effect; (iii) frames from both examples are symmetrical in both directions.

\subsection{Example 1: 5 -storey spatial RC frame}

\subsubsection{Model description and load vector analysis}

The 5-storey spatial RC frame with dimensions as shown in Figure $2 \mathrm{a}$ is analysed. Beam dimensions and discretisation of their cross-sections are shown in Figures $2 \mathrm{~d}$ and $2 \mathrm{e}$, while columns are presented in Figure 2f. Cross-sectional properties are allocated to the frame as shown in Figure 2c. The load distribution is assigned across beams as shown in Figure 2b, while concentrated forces are assigned in nodes at all beam and columns intercepts. Concentrated masses (cf. Figure $2 \mathrm{~b}$ ) and the material modulus $E=24.38 \mathrm{GPa}$ as the resulting modulus on the concrete model (cf. Figure $2 \mathrm{~h}$ ), are defined for the analysis of eigenvectors. The numerical model of concrete and reinforcing steel presented in Figures $2 \mathrm{~g}$ and $2 \mathrm{~h}$ is used for the analysis of the bearing capacity
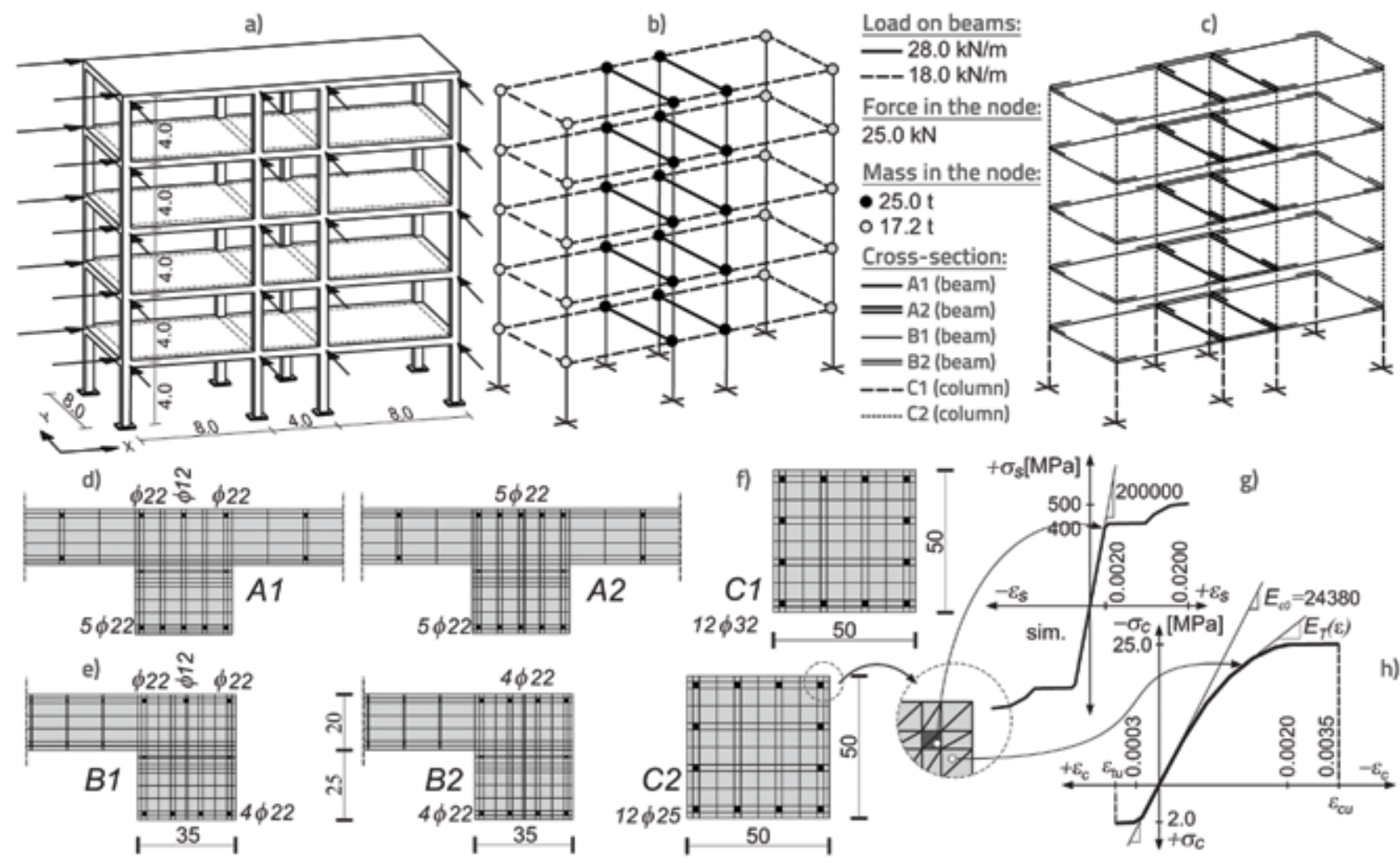

Figure 2. Example 1: space frame; b) load on beams and concentrated masses; c) cross-section marks; d)-f) cross-section discretisation; g) reinforcing-steel model; h) concrete model 
Table 1. Horizontal load vector properties in $x$ direction

\begin{tabular}{|c|c|c|c|c|}
\hline Vector & $T_{i}[\mathrm{~s}]$ & $m_{e i}[\%]$ & $m_{e i}[\mathrm{t}]$ & $F_{f i}[\mathrm{kN}]$ \\
\hline$\Phi_{1}$ & 0,905 & 83,12 & 701,2 & 1694 \\
\hline$\Phi_{2}$ & 0,281 & 8,65 & 73,0 & 1813 \\
\hline$\Phi_{3}$ & 0,168 & 3,93 & 33,1 & 2752 \\
\hline$\Phi_{4}$ & 0,118 & 0,69 & 5,8 & 1712 \\
\hline$\Phi_{5}$ & 0,113 & 0,59 & 5,0 & 1955 \\
\hline
\end{tabular}

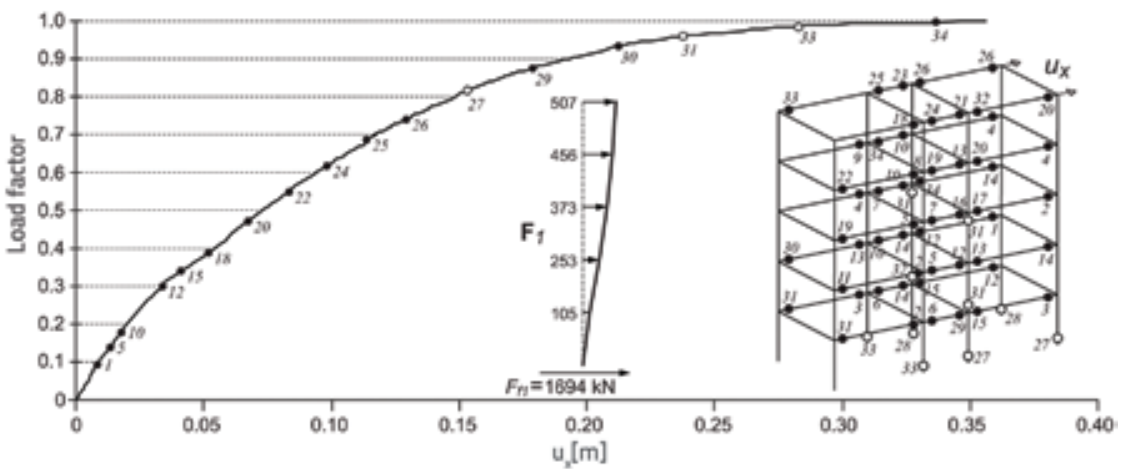

Figure 3. Bearing capacity curve for vector $\varphi_{1}$ (direction $\mathrm{x}$ ), and the cross-section plastification order

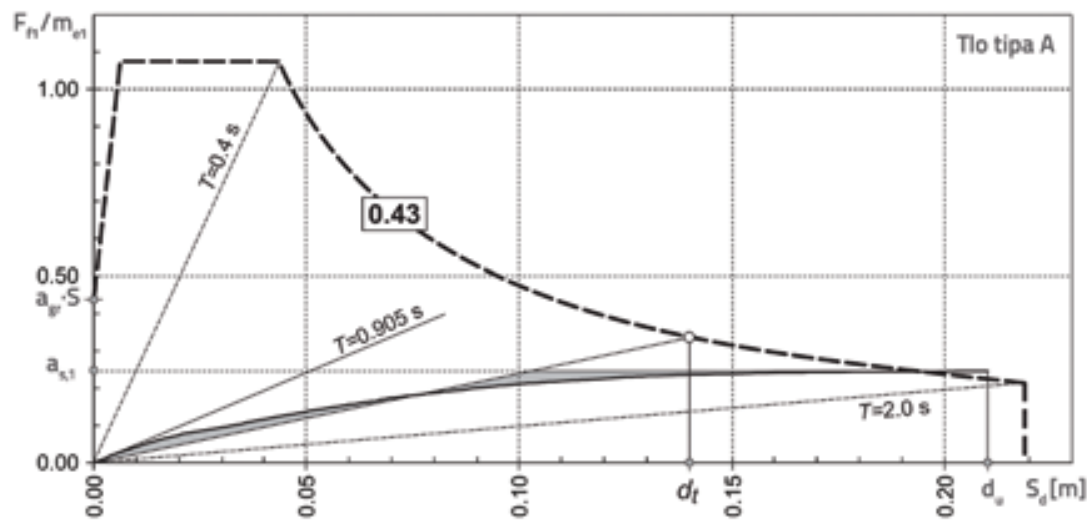

Figure 4. Seismic resistance analysis for the first vector (F1)

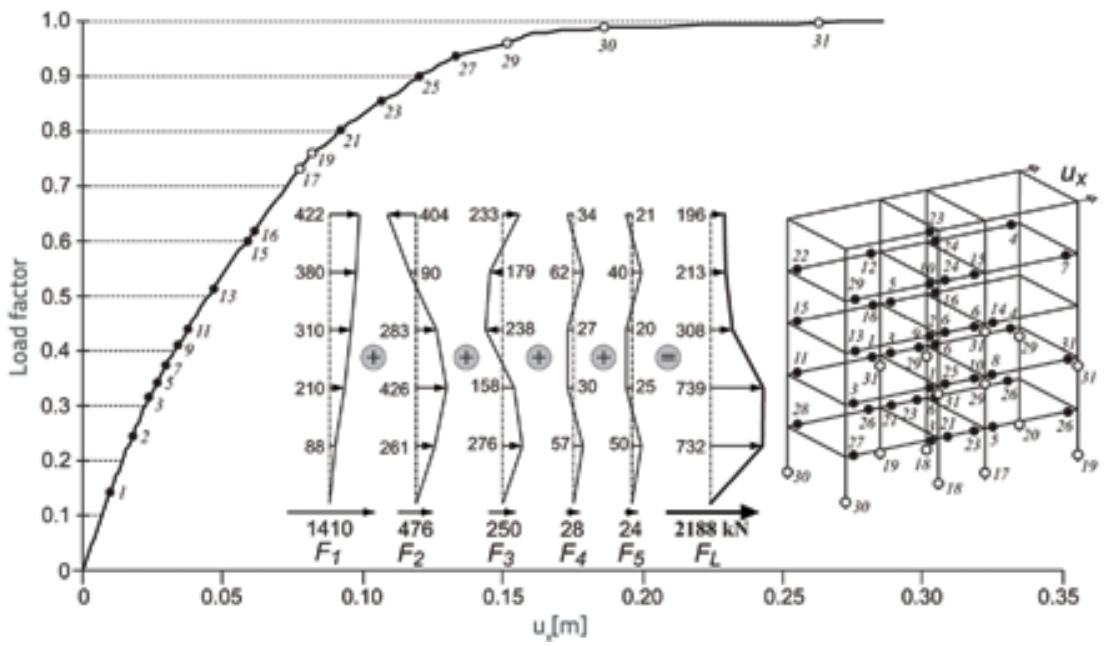

Figure 5. Bearing capacity curve for linear combination of modes and $x$ direction curve. The total weight of the model is $W=8280 \mathrm{kN}$, and the total mass of the model is $M=844.0$ tons.

Eigenvectors $\phi_{i}$ and the data on the corresponding periods $\mathrm{T}_{\mathrm{i}}$ and participating masses $m_{\text {ei }}$ are obtained through resolution of the linear dynamic task, as shown in Table 1.

The distribution and intensity of lateral horizontal forces on the frame are determined according to the expression (1). The resulting vector of horizontal load is monotonously increased in the nonlinear analysis until failure, i.e. until the critical load factor is achieved. The sum of all horizontal forces results in the failure force $F_{f i}$ for each individual eigenvector.

The form of the first load vector in the limit state, the corresponding bearing capacity curve, and the order of occurrence of plastification hinges, are presented in Figure 3 for the direction $x$. The early start of plastification is due to the realization of load in the way typical for the pushover method, where the vertical gravity load is imposed in the first phase, and the horizontal seismic load in the second phase. Therefore, the plastification starts immediately after the start of the second loading phase.

The conversion of the bearing capacity curve into the ADRS format, determination of elastoplastic equivalent, and limit target ground acceleration according to EN 1998, are shown in Figure 4 for the first mode and for the direction $\mathrm{x}$.

\subsubsection{Determination of target acceleration for $\mathbf{x}$ direction}

During determination of target acceleration, the target acceleration obtained for the first vector, i.e. $a_{g r, 1}=$ $0.43 \mathrm{~g}$, is assumed in the first step as the starting acceleration. a similar procedure is made for the remaining modes. The trial method procedure, with the result for minimum $a_{g r}$, value for the case of target acceleration of linear combination of modes for $x$ direction, is presented in Table 2. The target acceleration obtained amounts to $a_{g r, t}=0.205 \mathrm{~g}$. The corresponding force in the cross-section at the base of the calculation model (2188 $\mathrm{kN}$ ) is not the smallest failure force. 
Table 2. Target acceleration at linear combination of modes for $x$ direction

\begin{tabular}{|c|c|c|c|c|c|c|c|c|c|c|c|c|c|c|c|c|c|c|}
\hline$a_{g r, i}$ & $a_{s, 1}$ & $F_{1}$ & $a_{s, 2}$ & $F_{2}$ & $a_{s, 3}$ & $F_{3}$ & $a_{s, 4}$ & $F_{4}$ & $a_{5,5}$ & $F_{5}$ & $\Sigma F_{i}$ & $F_{L}$ & $F_{L} / \Sigma F_{i}$ & $\delta_{1}$ & $\delta_{2}$ & $\delta_{3}$ & $\delta_{4}$ & $\delta_{5}$ \\
\hline 0,43 & 0,247 & 1694 & 1,272 & 911 & 1,425 & 463 & 0,780 & 44,5 & 0,780 & 38,2 & 3156 & 2241 & 0,71 & 0,574 & 2,958 & 3,314 & 1,814 & 1,814 \\
\hline 0,25 & 0,224 & 1541 & 0,783 & 561 & 0,938 & 305 & 0,610 & 34,8 & 0,610 & 29,9 & 2471 & 2051 & 0,83 & 0,896 & 3,132 & 3,752 & 2,440 & 2,440 \\
\hline 0,21 & 0,207 & 1424 & 0,678 & 485 & 0,788 & 256 & 0,510 & 29,1 & 0,510 & 25,0 & 2220 & 2175 & 0,98 & 0,986 & 3,229 & 3,752 & 2,429 & 2,429 \\
\hline 0,205 & 0,205 & 1410 & 0,664 & 476 & 0,769 & 250 & 0,492 & 28,0 & 0,492 & 24,1 & 2188 & 2188 & 1,00 & 1,000 & 3,239 & 3,751 & 2,400 & 2,400 \\
\hline 0,20 & 0,202 & 1390 & 0,652 & 467 & 0,750 & 244 & 0,483 & 27,5 & 0,483 & 23,7 & 2151 & 2194 & 1,02 & 1,010 & 3,260 & 3,750 & 2,415 & 2,415 \\
\hline 0,18 & 0,189 & 1300 & 0,585 & 419 & 0,675 & 219 & 0,443 & 25,3 & 0,443 & 21,7 & 1985 & 2204 & 1,11 & 1,050 & 3,250 & 3,750 & 2,461 & 2,461 \\
\hline
\end{tabular}

Table 3. Target acceleration for the root (SRSS) combination of modes and for $x$ direction

\begin{tabular}{|c|c|c|c|c|c|c|c|c|c|c|c|c|c|c|c|c|c|c|c|}
\hline$a_{g r i}$ & $a_{s, 1}$ & $F_{1}$ & $a_{g r, i} / 2$ & $a_{s, 2}$ & $F_{2}$ & $a_{s, 3}$ & $F_{3}$ & $a_{s, 4}$ & $F_{4}$ & $a_{s, 5}$ & $F_{5}$ & $\Sigma F_{i}$ & $F_{S R S S}$ & $F_{L} / \Sigma F_{i}$ & $\delta_{1}$ & $\delta_{2}$ & $\delta_{3}$ & $\delta_{4}$ & $\delta_{5}$ \\
\hline 0,43 & 0,247 & 1699 & 0,215 & 0,678 & 485 & 0,806 & 262 & 0,510 & 29,1 & 0,510 & 25,0 & 2501 & 2201 & 0,88 & 0,574 & 1,577 & 1,874 & 1,186 & 1,186 \\
\hline 0,27 & 0,233 & 1603 & 0,135 & 0,426 & 305 & 0,506 & 165 & 0,315 & 18,0 & 0,315 & 15,4 & 2106 & 2106 & 1,00 & 0,863 & 1,578 & 1,874 & 1,167 & 1,167 \\
\hline 0,25 & 0,224 & 1541 & 0,125 & 0,400 & 286 & 0,469 & 152 & 0,285 & 16,2 & 0,285 & 14,0 & 2010 & 2050 & 1,02 & 0,896 & 1,600 & 1,876 & 1,140 & 1,140 \\
\hline 0,20 & 0,202 & 1390 & 0,100 & 0,332 & 238 & 0,375 & 122 & 0,233 & 13,3 & 0,233 & 11,4 & 1774 & 2040 & 1,15 & 1,010 & 1,660 & 1,875 & 1,165 & 1,165 \\
\hline
\end{tabular}

Load vectors for all participating models, bearing capacity curves, and the order of occurrence of plastification hinges for linear combination of modes and for $\mathrm{x}$ direction, are presented in Figure 5.

Results for the root(SRSS) combination of modes and for $x$ direction are presented in Table 3 . The target acceleration amounts to $a_{g r, t}=$ $0.27 \mathrm{~g}$. It can be concluded by comparing target accelerations that the linear combination of modes is less favourable than the root combination (SRSS) as the structural failure occurs at the lower target acceleration $\left(a_{g r, t}=0,205 \mathrm{~g}\right)$, unlike the target acceleration for the SRSS combination $\left(a_{g r, t}=0,27 \mathrm{~g}\right)$.

Load vectors for participating modes, bearing capacity curves, and the order of occurrence of plastification hinges for the root (SRSS) combination of modes and for $x$ direction, are presented in Figure 6.

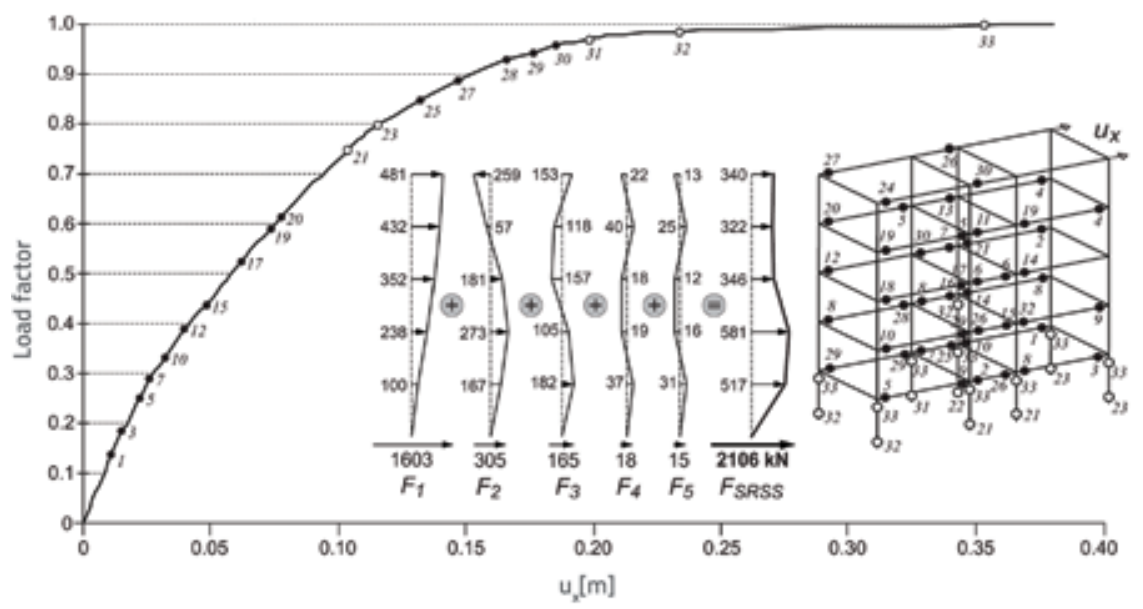

Figure 6. Bearing capacity curve for the root (SRSS) combination of modes and for $x$ direction

\subsubsection{Determination of target acceleration for y direction}

Analysis results for y direction are presented below. Load vector properties for each individual mode are presented in Table 4.

Table 4. Horizontal load vector properties for $y$ direction

\begin{tabular}{|c|c|c|c|c|}
\hline Vector & $T_{i}[\mathrm{~s}]$ & $\boldsymbol{m}_{e i}[\%]$ & $\boldsymbol{m}_{e i}[\mathrm{t}]$ & $\boldsymbol{F}_{f i}[\mathrm{kN}]$ \\
\hline$\Phi_{1}$ & 1,002 & 81,97 & 691,8 & 1418 \\
\hline$\Phi_{2}$ & 0,317 & 10,43 & 88,0 & 1563 \\
\hline$\Phi_{3}$ & 0,176 & 4,14 & 34,9 & 2436 \\
\hline$\Phi_{4}$ & 0,119 & 1,92 & 16,2 & 2225 \\
\hline$\Phi_{5}$ & 0,094 & 0,63 & 5,3 & 1180 \\
\hline
\end{tabular}

Determination of target acceleration for the linear combination of modes for $y$ direction is shown in Table 5. The target acceleration obtained for the first vector, i.e. $a_{g r, 1}=0.52 \mathrm{~g}$, is taken to be the initial acceleration in the first step. The target acceleration obtained amounts to $a_{g, t}=0.17 \mathrm{~g}$.

Figure 7 shows load vectors of all participating modes, bearing capacity curves, and the order of occurrence of plastification hinges for the linear combination of modes and for $y$ direction.

Definition of target acceleration for the SRSS combination of modes and for $y$ direction is shown in Table 6. The 
Table 5. Target acceleration at linear combination of modes for $y$ direction

\begin{tabular}{|c|c|c|c|c|c|c|c|c|c|c|c|c|c|c|c|c|c|c|}
\hline$a_{g r, i}$ & $a_{s, 1}$ & $F_{1}$ & $a_{s, 2}$ & $F_{2}$ & $a_{s, 3}$ & $F_{3}$ & $a_{s, 4}$ & $\mathrm{~F}_{4}$ & $a_{s, 5}$ & $F_{5}$ & $\Sigma F_{i}$ & $F_{L}$ & $F_{L} / \Sigma F_{i}$ & $\delta_{1}$ & $\delta_{2}$ & $\delta_{3}$ & $\delta_{4}$ & $\delta_{5}$ \\
\hline 0,52 & 0,209 & 1418 & 1,355 & 1169 & 1,950 & 669 & 0,975 & 155 & 0,765 & 39,8 & 3451 & 2105 & 0,61 & 0,402 & 2,606 & 3,750 & 1,875 & 1,471 \\
\hline 0,34 & 0,195 & 1323 & 0,976 & 842 & 1,275 & 437 & 0,638 & 101 & 0,510 & 26,5 & 2731 & 2021 & 0,74 & 0,574 & 2,871 & 3,750 & 1,876 & 1,500 \\
\hline 0,20 & 0,183 & 1242 & 0,631 & 545 & 0,750 & 257 & 0,383 & 61 & 0,300 & 15,6 & 2120 & 1929 & 0,91 & 0,915 & 3,155 & 3,750 & 1,915 & 1,500 \\
\hline 0,17 & 0,166 & 1126 & 0,535 & 462 & 0,638 & 219 & 0,525 & 84 & 0,413 & 21,4 & 1912 & 1912 & 1,00 & 0,976 & 3,147 & 3,753 & 3,088 & 2,429 \\
\hline 0,15 & 0,153 & 1038 & 0,495 & 427 & 0,563 & 193 & 0,495 & 79 & 0,390 & 20,3 & 1757 & 1863 & 1,06 & 1,020 & 3,300 & 3,753 & 3,300 & 2,600 \\
\hline
\end{tabular}

Table 6. Target acceleration for the root (SRSS) combination of modes and for $y$ direction

\begin{tabular}{|c|c|c|c|c|c|c|c|c|c|c|c|c|c|c|c|c|c|c|c|}
\hline$a_{g r, i}$ & $a_{s, 1}$ & $F_{1}$ & $a_{g r, i} / 2$ & $a_{s, 2}$ & $F_{2}$ & $a_{s, 3}$ & $F_{3}$ & $a_{s, 4}$ & $F_{4}$ & $a_{s, 5}$ & $F_{5}$ & $\Sigma F_{i}$ & $F_{S R S S}$ & $F_{S R S S} / \Sigma F_{i}$ & $\delta_{1}$ & $\delta_{2}$ & $\delta_{3}$ & $\delta_{4}$ & $\delta_{5}$ \\
\hline 0,52 & 0,209 & 1418 & 0,26 & 0,750 & 647 & 0,975 & 334 & 0,443 & 70,4 & 0,342 & 17,8 & 2488 & 1965 & 0,79 & 0,402 & 1,442 & 1,875 & 0,852 & 0,658 \\
\hline 0,34 & 0,195 & 1323 & 0,17 & 0,530 & 457 & 0,638 & 219 & 0,285 & 45,3 & 0,225 & 11,7 & 2056 & 1871 & 0,91 & 0,574 & 1,559 & 1,876 & 0,838 & 0,662 \\
\hline 0,22 & 0,189 & 1282 & 0,11 & 0,389 & 336 & 0,413 & 142 & 0,165 & 26,2 & 0,158 & 8,2 & 1794 & 1758 & 0,98 & 0,859 & 1,768 & 1,877 & 0,750 & 0,718 \\
\hline 0,21 & 0,186 & 1262 & 0,105 & 0,380 & 328 & 0,394 & 135 & 0,150 & 23,9 & 0,147 & 7,6 & 1756 & 1757 & 1,00 & 0,886 & 1,810 & 1,876 & 0,714 & 0,700 \\
\hline 0,20 & 0,183 & 1242 & 0,10 & 0,347 & 300 & 0,375 & 129 & 0,135 & 21,5 & 0,130 & 6,8 & 1698 & 1732 & 1,02 & 0,915 & 1,735 & 1,875 & 0,675 & 0,650 \\
\hline
\end{tabular}

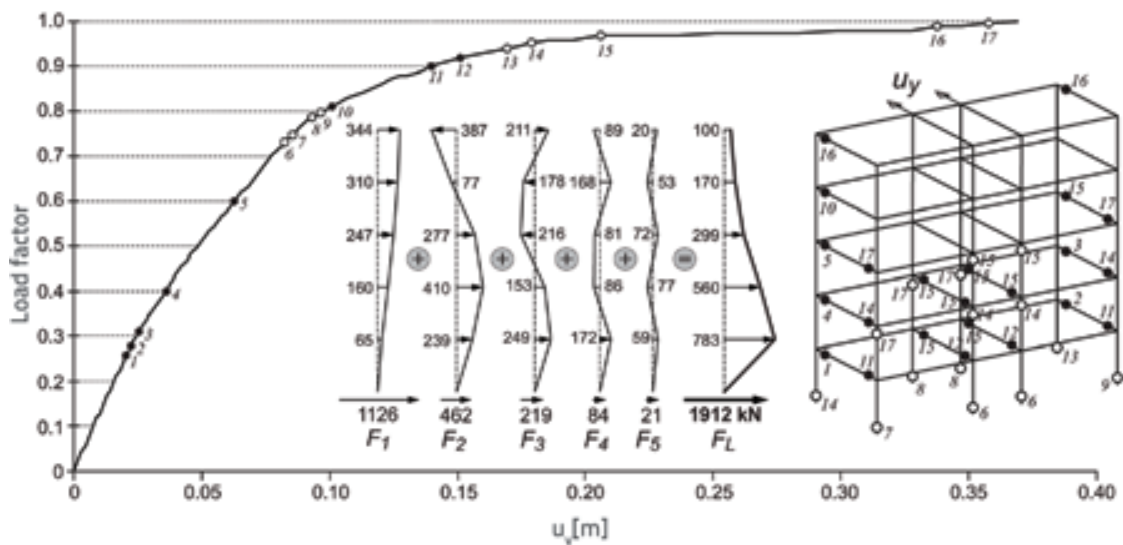

Figure 7. Bearing capacity curve for linear combination of modes for $y$ direction

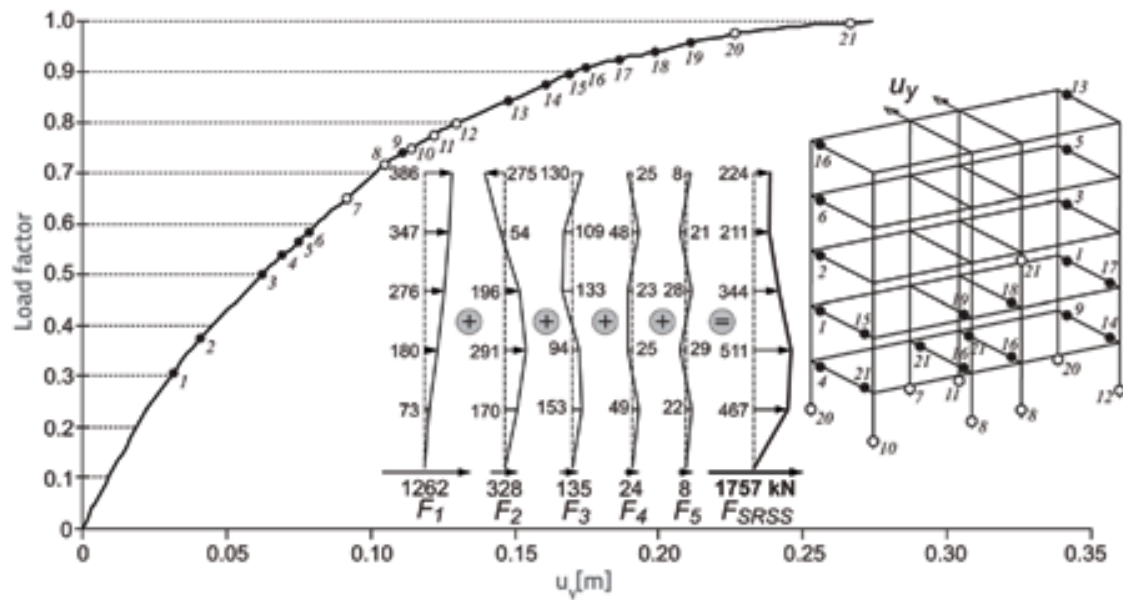

Figure 8. Bearing capacity curve for the root (SRSS) combination of modes and for $y$ direction target acceleration amounts to $a_{g r, t}=$ $0.21 \mathrm{~g}$. It was established that the linear combination is relevant for the direction $y$ as well, because the structural failure occurs at a lower target acceleration ( $a_{g r, t}$ $=0.17 \mathrm{~g}$ ), unlike the target acceleration for the root combination ( $a_{g r, t}=0.21 \mathrm{~g}$ ). Figure 8 shows load vectors of participating modes, bearing capacity curves, and the order of occurrence of plastification hinges for the SRSS combination of modes and for $y$ direction.

\subsection{Example 2: 9-storey spatial RC frame}

\subsubsection{Model description and load vector analysis}

The 9-storey spatial RC frame with dimensions as shown in Figure 9a is analysed. Beam dimensions and discretisation of their cross-sections are shown in Figures 9d and 9e, while columns are presented in Figure 9f. Cross-sectional properties are allocated to the frame as shown in Figure 9c. The load distribution is assigned across beams as shown in Figure 9b, while concentrated forces are assigned in 
a)

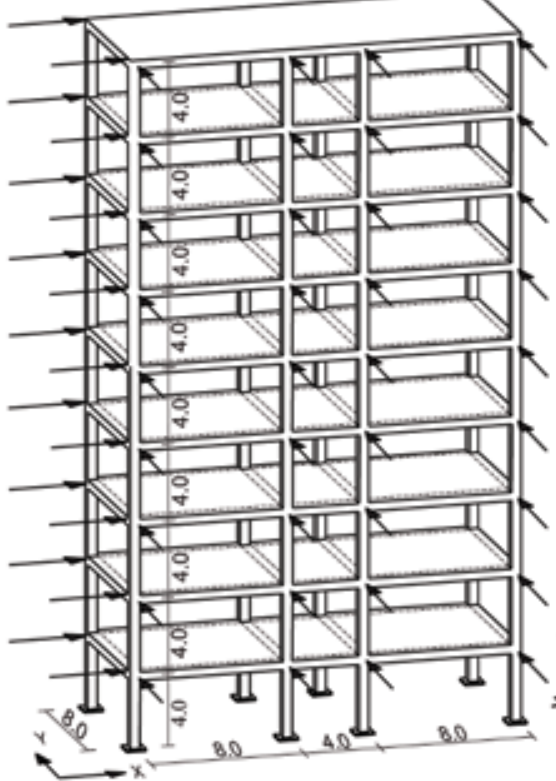

b)

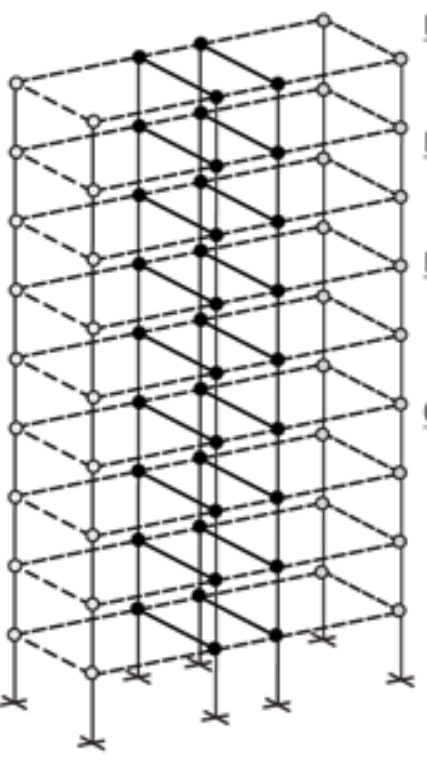

c)

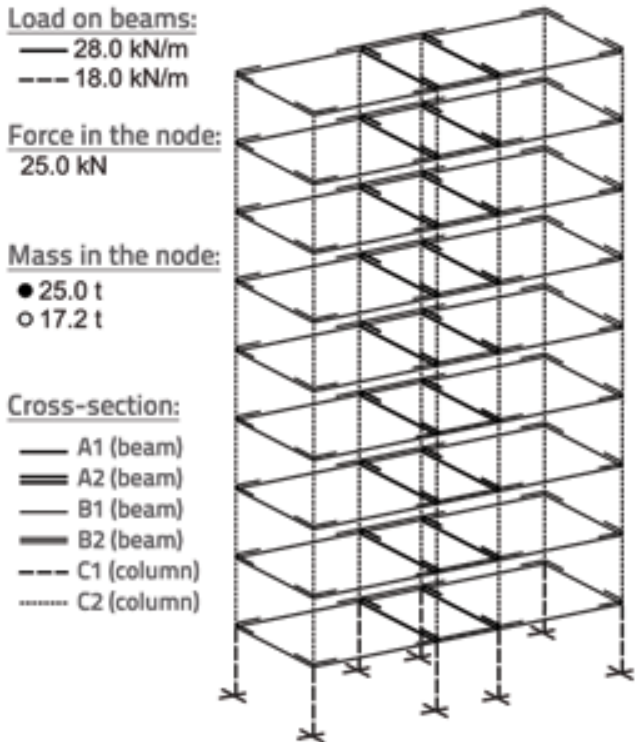

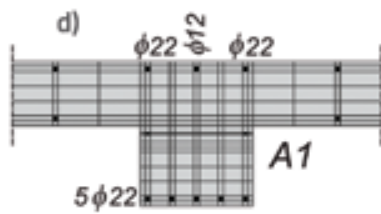

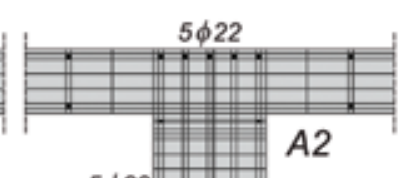

f)
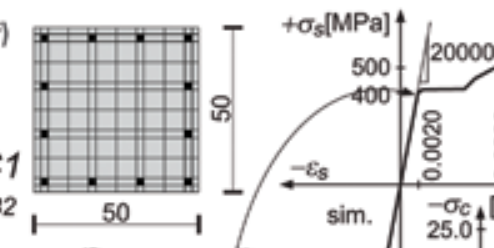

g)

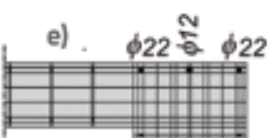

B1
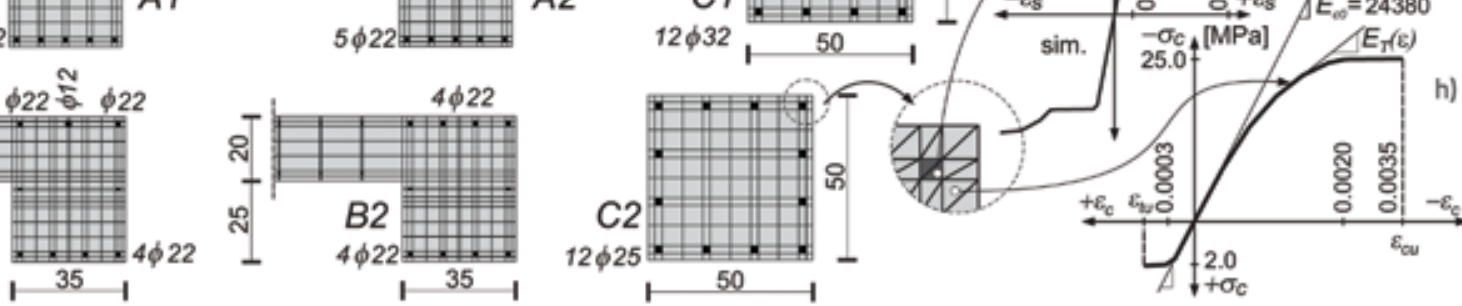

Figure 9. Example 2: a) space frame; b) load on girders and concentrated masses; c) cross-section marks; d)-f) cross-section discretisation; g) reinforcing-steel model; h) concrete model

nodes at all beam and columns intercepts. Concentrated masses (cf. Figure 9b) and the material modulus $E=24.38 \mathrm{GPa}$ as the resulting modulus on the concrete model (cf. Figure 9h), are defined for the analysis of eigenvectors. The numerical model of concrete and reinforcing steel presented in Figures $9 \mathrm{~g}$ and $9 \mathrm{~h}$ is used for the analysis of the bearing capacity curve. The total weight of the model is $W=14903 \mathrm{kN}$, and the total mass of the model is $M=1519.2$ tons.

Eigenvectors $\phi_{\mathrm{i}}$ and the data on the corresponding periods $T_{i}$ and participating masses $\mathrm{m}_{\mathrm{ei}}$ are obtained through resolution of the linear dynamic task, as shown in Table 7.

Table 7. Horizontal load vector properties in $x$ direction

\begin{tabular}{|c|c|c|c|c|}
\hline Vector & $T_{i}[\mathrm{~s}]$ & $\boldsymbol{m}_{e i}[\%]$ & $\mathrm{m}_{\mathrm{ei}}[\mathrm{t}]$ & $F_{f i}[\mathrm{kN}]$ \\
\hline$\Phi_{1}$ & 2,298 & 79,87 & 1213,4 & 1330 \\
\hline$\Phi_{2}$ & 0,746 & 10,37 & 157,5 & 1530 \\
\hline$\Phi_{3}$ & 0,420 & 3,87 & 58,8 & 2035 \\
\hline$\Phi_{4}$ & 0,282 & 2,20 & 33,4 & 1770 \\
\hline$\Phi_{5}$ & 0,207 & 1,38 & 21,0 & 2490 \\
\hline
\end{tabular}

\subsubsection{Determination of target acceleration for $\mathbf{x}$ direction}

The determination of target acceleration of the linear combination of modes for the direction $\mathrm{x}$ is shown in Table 8 . The target acceleration obtained for the first vector, amounting to $a_{g r, 1}=0.92$ $\mathrm{g}$, is assumed to be the initial acceleration in the first step. The target acceleration obtained amounts to $a_{\text {gr,t }}=0.19 \mathrm{~g}$.

Load vectors for all participating models, bearing capacity curves, and the order of occurrence of plastification hinges for linear combination of modes and for $\mathrm{x}$ direction, are presented in Figure 10.

Results for the root (SRSS) combination of modes and for $x$ direction are presented in Table 9. The target acceleration amounts to $a_{g r, t}=0.25 \mathrm{~g}$. It can be concluded by comparing target accelerations that the linear combination of modes for the 9-storey frame is significantly less favourable than the root combination (SRSS) because the structural failure occurs at lower target acceleration $\left(a_{\text {gr.t }}=0.19 \mathrm{~g}\right.$ ), unlike the target acceleration for the SRSS combination $\left(a_{g r, t}=0.257 \mathrm{~g}\right.$ ), which is the same case as in the 5-storey frame. 
Table 8. Target acceleration at linear combination of modes for the $x$ direction

\begin{tabular}{|c|c|c|c|c|c|c|c|c|c|c|c|c|c|c|c|c|c|c|}
\hline$a_{g r, i}$ & $a_{s, 1}$ & $F_{1}$ & $a_{s, 2}$ & $F_{2}$ & $a_{s, 3}$ & $F_{3}$ & $a_{s, 4}$ & $F_{4}$ & $a_{5,5}$ & $F_{5}$ & $\Sigma F_{i}$ & $F_{L}$ & $F_{L} / \Sigma F_{i}$ & $\delta_{1}$ & $\delta_{2}$ & $\delta_{3}$ & $\delta_{4}$ & $\delta_{5}$ \\
\hline 0,92 & 0,112 & 1330 & 0,923 & 1426 & 2,239 & 1292 & 2,700 & 886 & 3,161 & 651 & 5585 & 2681 & 0,48 & 0,121 & 1,003 & 2,434 & 2,935 & 3,436 \\
\hline 0,50 & 0,107 & 1274 & 0,694 & 1072 & 1,428 & 824 & 1,749 & 574 & 1,858 & 383 & 4126 & 2476 & 0,60 & 0,214 & 1,388 & 2,856 & 3,498 & 3,716 \\
\hline 0,20 & 0,073 & 869 & 0,448 & 692 & 0,689 & 398 & 0,750 & 246 & 0,750 & 155 & 2359 & 2123 & 0,90 & 0,365 & 2,240 & 3,445 & 3,750 & 3,750 \\
\hline 0,19 & 0,071 & 845 & 0,318 & 491 & 0,660 & 381 & 0,713 & 234 & 0,713 & 147 & 2098 & 2098 & 1,00 & 0,374 & 1,674 & 3,474 & 3,753 & 3,753 \\
\hline 0,18 & 0,068 & 809 & 0,307 & 474 & 0,623 & 359 & 0,675 & 221 & 0,675 & 139 & 2004 & 2164 & 1,08 & 0,378 & 1,706 & 3,461 & 3,750 & 3,750 \\
\hline
\end{tabular}

Table 9. Target acceleration for the root (SRSS) combination of modes and for $x$ direction

\begin{tabular}{|c|c|c|c|c|c|c|c|c|c|c|c|c|c|c|c|c|c|c|c|}
\hline$a_{g r, i}$ & $a_{s, 1}$ & $F_{1}$ & $a_{g r, i} / 2$ & $a_{s, 2}$ & $F_{2}$ & $a_{s, 3}$ & $F_{3}$ & $a_{s, 4}$ & $F_{4}$ & $a_{s, 5}$ & $F_{5}$ & $\Sigma F_{i}$ & $F_{S R S S}$ & $F_{\text {SRSS }} / \Sigma F_{i}$ & $\delta_{1}$ & $\delta_{2}$ & $\delta_{3}$ & $\delta_{4}$ & $\delta_{5}$ \\
\hline 0,92 & 0,112 & 1330 & 0,46 & 0,651 & 1006 & 1,350 & 779 & 1,637 & 537 & 1,725 & 355 & 4010 & 2085 & 0,52 & 0,122 & 0,708 & 1,467 & 1,779 & 1,875 \\
\hline 0,50 & 0,107 & 1274 & 0,25 & 0,391 & 604 & 0,845 & 488 & 0,938 & 308 & 0,938 & 193 & 2866 & 2064 & 0,72 & 0,214 & 0,782 & 1,690 & 1,876 & 1,876 \\
\hline 0,30 & 0,093 & 1107 & 0,15 & 0,260 & 402 & 0,523 & 302 & 0,538 & 176 & 0,563 & 116 & 2103 & 2439 & 1,16 & 0,310 & 0,867 & 1,743 & 1,793 & 1,877 \\
\hline 0,25 & 0,085 & 1011 & 0,125 & 0,225 & 348 & 0,442 & 255 & 0,469 & 154 & 0,469 & 97 & 1865 & 1865 & 1,00 & 0,340 & 0,900 & 1,768 & 1,876 & 1,876 \\
\hline 0,20 & 0,073 & 869 & 0,10 & 0,182 & 281 & 0,354 & 204 & 0,375 & 123 & 0,375 & 77 & 1555 & 1368 & 0,88 & 0,365 & 0,910 & 1,770 & 1,875 & 1,875 \\
\hline
\end{tabular}

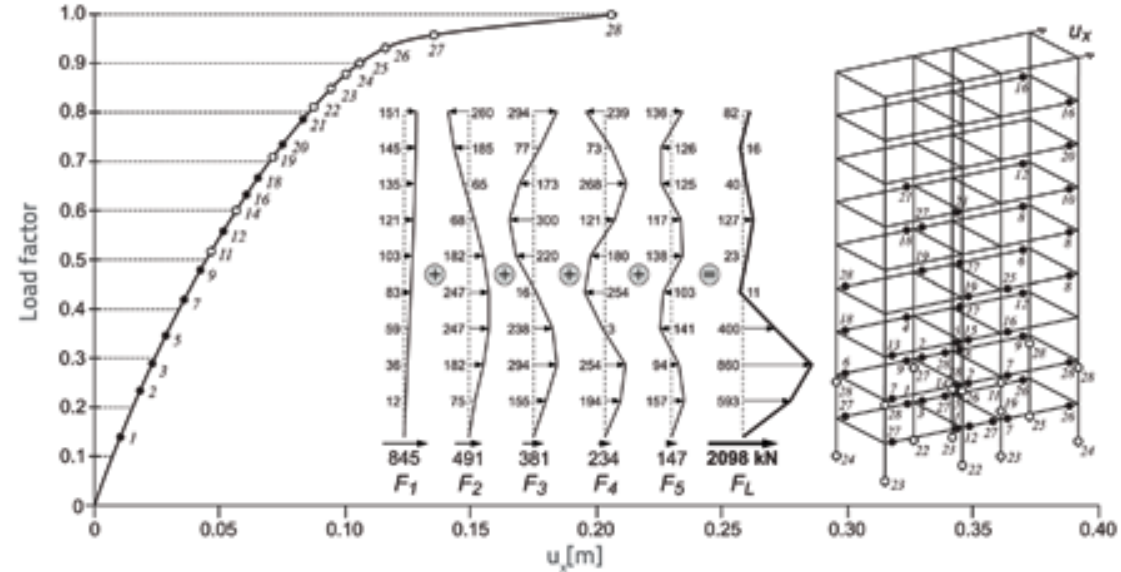

Figure 10. Bearing capacity curve for linear combination of modes for $\mathrm{x}$ direction

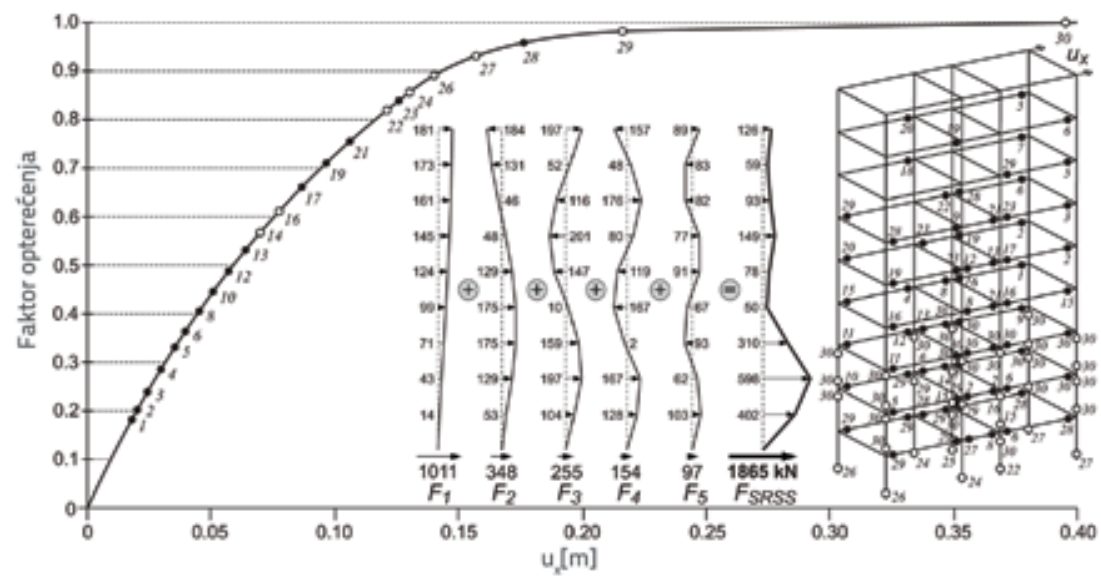

Figure 11. Bearing capacity curve for the root (SRSS) combination of modes and for $x$ direction
Load vectors for all participating modes, bearing capacity curves, and the order of occurrence of plastification hinges for the root (SRSS) combination of modes and for $\mathrm{x}$ direction, are presented in Figure 11 .

\subsubsection{Determination of target acceleration for y direction}

Analysis results for $y$ direction are presented below. Load vector properties for each individual mode are presented in Table 10.

Table 10. Horizontal load vector properties for $y$ direction

\begin{tabular}{|c|c|c|c|c|}
\hline Vector & $T_{i}[\mathrm{~s}]$ & $\boldsymbol{m}_{e i}[\%]$ & $\mathrm{m}_{\mathrm{ei}}[\mathrm{t}]$ & $F_{f i}[\mathrm{kN}]$ \\
\hline$\Phi_{1}$ & 2,715 & 78,91 & 1198,8 & 1410 \\
\hline$\Phi_{2}$ & 0,869 & 10,59 & 160,9 & 1735 \\
\hline$\Phi_{3}$ & 0,478 & 4,10 & 62,3 & 1965 \\
\hline$\Phi_{4}$ & 0,317 & 1,60 & 24,3 & 2340 \\
\hline$\Phi_{5}$ & 0,224 & 1,40 & 21,3 & 2435 \\
\hline
\end{tabular}

Determination of target acceleration for the linear combination of modes for $y$ direction is shown in Table 11. The target acceleration obtained for the first vector, i.e. $a_{g r, 1}=1.05 \mathrm{~g}$, is taken to be the initial acceleration in the 
Table 11. Target acceleration at linear combination of modes for $y$ direction

\begin{tabular}{|c|c|c|c|c|c|c|c|c|c|c|c|c|c|c|c|c|c|c|}
\hline$a_{g r, i}$ & $a_{s, 1}$ & $F_{1}$ & $a_{s, 2}$ & $F_{2}$ & $a_{s, 3}$ & $F_{3}$ & $a_{s, 4}$ & $F_{4}$ & $a_{s, 5}$ & $F_{5}$ & $\Sigma F_{i}$ & $F_{L}$ & $F_{L} / \Sigma F_{i}$ & $\delta_{1}$ & $\delta_{2}$ & $\delta_{3}$ & $\delta_{4}$ & $\delta_{5}$ \\
\hline 1,05 & 0,120 & 1410 & 0,917 & 1447 & 2,313 & 1413 & 3,900 & 928 & 3,606 & 754 & 5952 & 2619 & 0,44 & 0,114 & 0,873 & 2,203 & 3,714 & 3,434 \\
\hline 0,40 & 0,097 & 1141 & 0,494 & 780 & 1,063 & 649 & 1,500 & 357 & 1,500 & 314 & 3240 & 2203 & 0,68 & 0,243 & 1,235 & 2,658 & 3,750 & 3,750 \\
\hline 0,20 & 0,063 & 741 & 0,309 & 488 & 0,588 & 359 & 0,750 & 179 & 0,750 & 157 & 1923 & 1846 & 0,96 & 0,315 & 1,545 & 2,940 & 3,750 & 3,750 \\
\hline 0,18 & 0,058 & 682 & 0,277 & 437 & 0,537 & 328 & 0,675 & 161 & 0,675 & 141 & 1749 & 1749 & 1,00 & 0,322 & 1,539 & 2,983 & 3,750 & 3,750 \\
\hline 0,17 & 0,056 & 659 & 0,265 & 418 & 0,500 & 306 & 0,638 & 152 & 0,638 & 133 & 1667 & 1834 & 1,10 & 0,329 & 1,559 & 2,941 & 3,753 & 3,753 \\
\hline
\end{tabular}

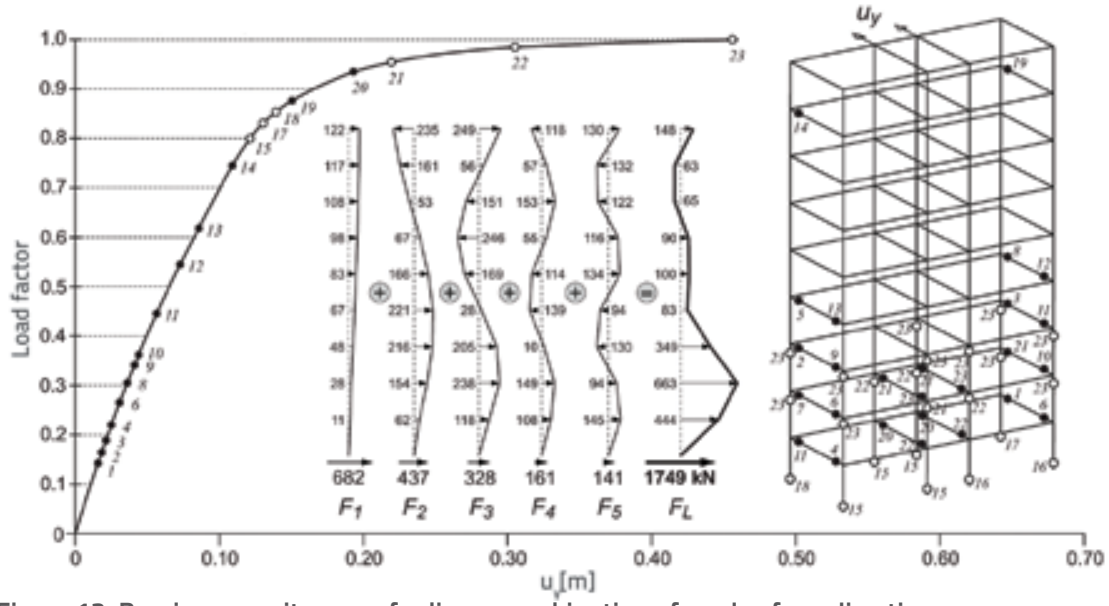

Figure 12. Bearing capacity curve for linear combination of modes for $y$ direction

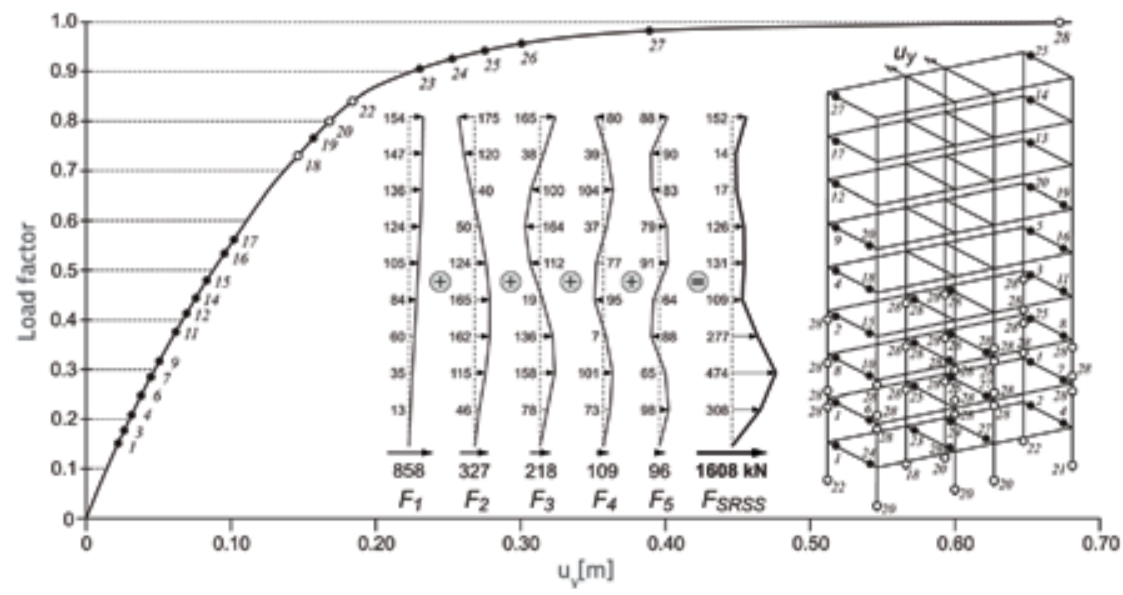

Figure 13. Bearing capacity curve for the root (SRSS) combination of modes for $y$ direction

Table 12. Target acceleration for the root (SRSS) combination of modes and for $y$ direction first step. The target acceleration obtained amounts to $a_{g r . t}=0.18 \mathrm{~g}$.

Figure 12 shows load vectors of all participating modes, bearing capacity curves, and the order of occurrence of plastification hinges for the linear combination of modes and for $y$ direction. Definition of target acceleration for the root (SRSS) combination of modes and for y direction is shown in Table 12. The target acceleration amounts to $a_{g r, t}=0.245 \mathrm{~g}$. It was established that the linear combination of modes for the 9-storey frame is relevant for the direction $y$ as well, because the structural failure occurs at a lower target acceleration $\left(a_{g r, t}=0.18 \mathrm{~g}\right)$, unlike the target acceleration for the root (SRSS) combination ( $a_{g r, t}=0.245 \mathrm{~g}$ ), which is the same case as for the 5 -storey frame.

Figure 13 shows load vectors of participating modes, bearing capacity curve, and the order of occurrence of plastification hinges for the SRSS combination of modes and for $y$ direction.

\section{Test of frequency of the linear (L) and root (SRSS) mode combinations}

The objective of the following procedure is to check which of the two mode combinations is more probable based

\begin{tabular}{|c|c|c|c|c|c|c|c|c|c|c|c|c|c|c|c|c|c|c|c|}
\hline$a_{g, i}$ & $a_{s, 1}$ & $F_{1}$ & $a_{g r i} / 2$ & $a_{s, 2}$ & $F_{2}$ & $a_{s, 3}$ & $F_{3}$ & $a_{s, 4}$ & $F_{4}$ & $a_{s, 5}$ & $F_{5}$ & $\Sigma F_{i}$ & $F_{\text {SRSS }}$ & $F_{S R S S} / \Sigma F_{i}$ & $\delta_{1}$ & $\delta_{2}$ & $\delta_{3}$ & $\delta_{4}$ & $\delta_{5}$ \\
\hline 1,05 & 0,120 & 1410 & 0,525 & 0,610 & 963 & 1,300 & 794 & 1,968 & 468 & 1,879 & 393 & 4028 & 2175 & 0,54 & 0,114 & 0,581 & 1,238 & 1,874 & 1,790 \\
\hline 0,40 & 0,097 & 1141 & 0,20 & 0,309 & 488 & 0,588 & 359 & 0,750 & 179 & 0,750 & 157 & 2323 & 1812 & 0,78 & 0,243 & 0,773 & 1,470 & 1,875 & 1,875 \\
\hline 0,245 & 0,073 & 858 & 0,123 & 0,207 & 327 & 0,357 & 218 & 0,459 & 109 & 0,459 & 96 & 1608 & 1608 & 1,00 & 0,298 & 0,845 & 1,457 & 1,873 & 1,873 \\
\hline 0,24 & 0,072 & 847 & 0,12 & 0,203 & 320 & 0,350 & 214 & 0,450 & 107 & 0,450 & 94 & 1582 & 1661 & 1,05 & 0,300 & 0,846 & 1,458 & 1,875 & 1,875 \\
\hline 0,20 & 0,063 & 741 & 0,10 & 0,173 & 273 & 0,295 & 180 & 0,375 & 89 & 0,375 & 78 & 1362 & 1702 & 1,25 & 0,315 & 0,865 & 1,475 & 1,875 & 1,875 \\
\hline
\end{tabular}


on verification on a set of the following five selected realearthquake accelerograms: Montenegro - 1979, Campano Lucano (Italia) - 1980, Aigion (Greece) - 1995, Strofades (Greece) - 1997 and Olfus (Iceland) - 2008, as shown in Figure 14. Accelerogram records were taken from [18].

The verification is conducted on the linear and nonlinear levels for single-degree-of-freedom systems (SDOF) taken as modes obtained for RC frame models from examples 1 and 2 . The dynamic response for each SDOF was obtained using the Newmark's average acceleration method. The numerical integration was obtained using the computer program written in C++ according to the procedure presented in [19].

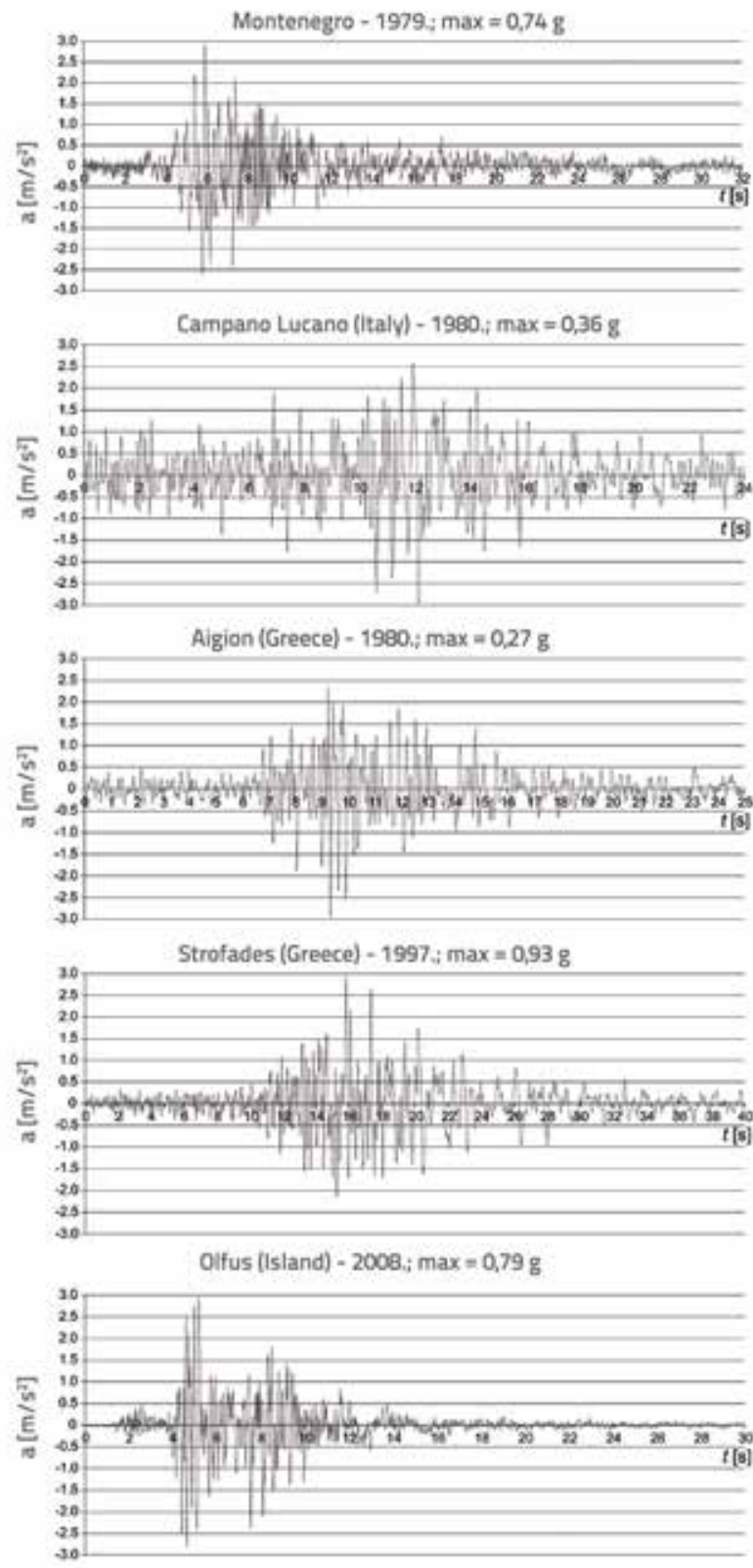

Figure 14. Accelerograms from five earthquake, [18]

\subsection{Verification of linear and root mode combinations on linear level}

First, the 5-storey RC space frame from example 1 is analysed. Transverse forces in cross-section were calculated based on the design model $\left(F_{i}\right)$ as time functions for each of the five eigenmodes. At that, the stiffness $k$ of the linear SDOF was defined via the known period $T_{i}$ and the corresponding participating mass $m_{r}$, which corresponds to an individual eigenvector $\phi_{i}$.

A relative force scale was introduced. According to this scale, the biggest force in all modes $\left(\left|F_{\max }\right|\right)$ is equal to 1.00 , and the value of other forces is determined in relation to this value.

Figure 15 shows the diagram of the transverse force in cross-section based on the design model $(F)$ dependent on time for all five eigenmodes for the example of the 5-storey RC framed subjected to load in $x$ direction through the Montenegro earthquake seismic excitation. It can be observed that, on the relative force scale, the biggest force in all five modes $\left(\left|F_{\max }\right|=1135 \mathrm{kN}\right)$ corresponds to the value of 1.00 .

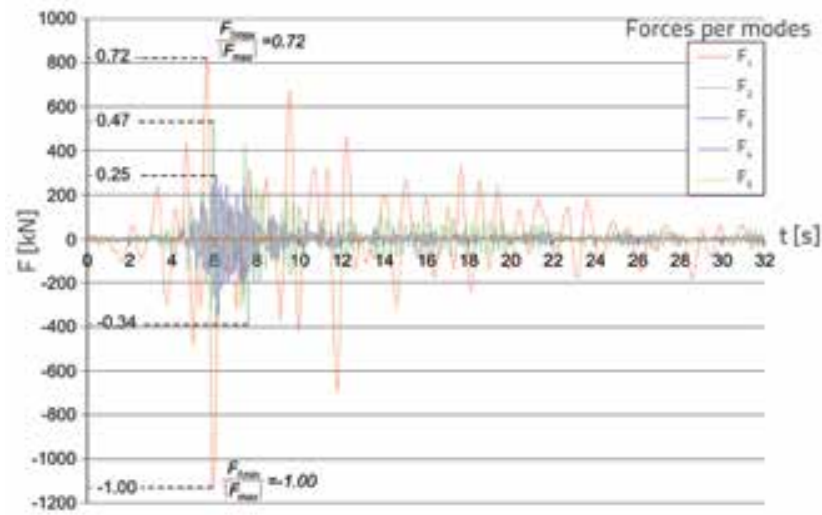

Figure 15. Transverse forces in cross section based on the design model for the 5-storey RC frame for all five modes, dependent on time, for the Montenegro seismic excitation in $\mathrm{x}$ direction

Maximum values of transverse forces in cross section based on calculation model for all modes shown in tables 13 to 16 , due to seismic action of five selected earthquake records, were obtained analogously.

Analysis results for the directions $x$ and $y$, given in Table 13, show simultaneously the least favourable combination of the linear superposition of modes $F_{L^{\prime}}$ and the least favourable combination of the square root of the sum of the squares $F_{S R S S}$ A similar procedure was conducted for the analysis of the 9-storey linear RC space frame from example 2, and the analysis results are given in Table 14.

Dynamic response results for the linear system, as given in tables 13 and 14 , show that the linear mode combination $F_{L}$ is more often unfavourable than the root combination of the sum of the squares $F_{\text {SRSS }}$. 
Table 13. Comparison of linear (L) and root (SRSS) mode combinations for the 5-storey RC frame
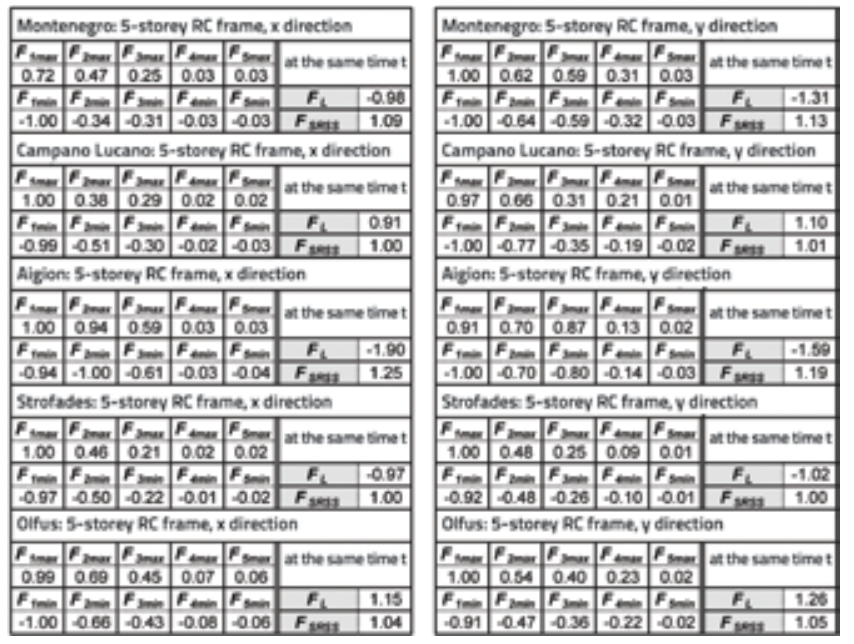

Table 15. Linear (L) and root (SRSS) combination of nonlinear model for the 5-storey RC frame
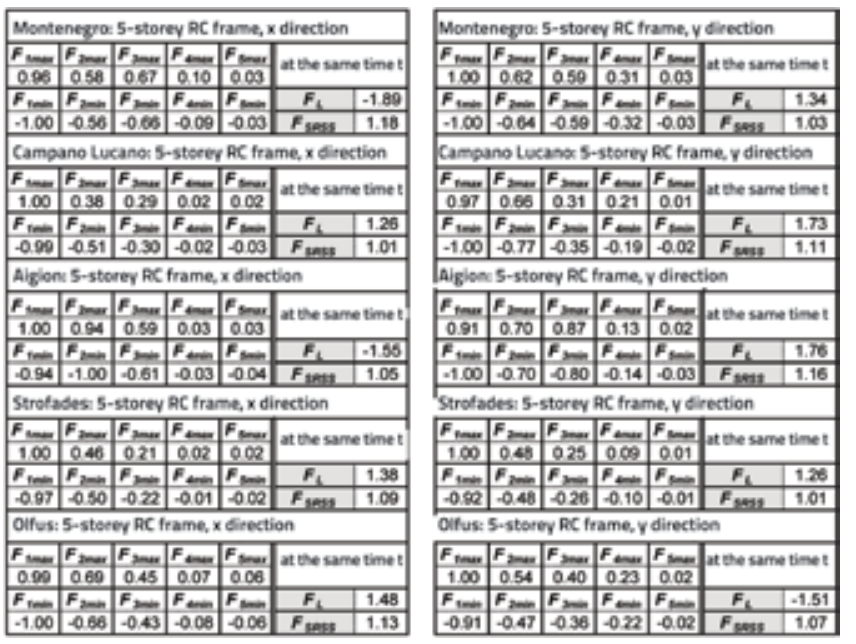

\subsection{Verification of linear and root mode combinations on nonlinear level}

The nonlinear level is realized by treating each mode as a single nonlinear SDOF. Nonlinear cyclic properties of the SDOF are generated from the corresponding bearing capacity curve as shown in Figure 16 and relation (6).

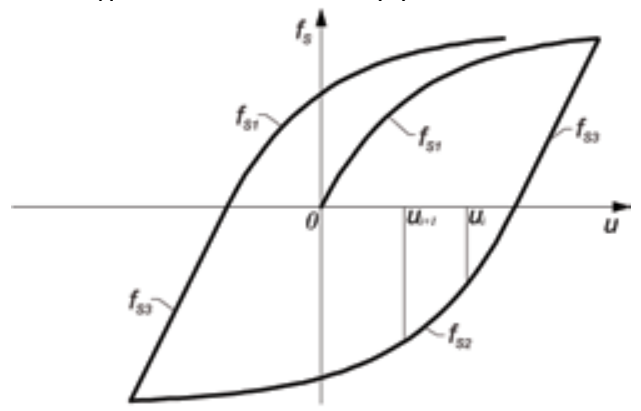

Figure 16. Cyclic bearing capacity curve for nonlinear system
Table 14. Comparison of linear (L) and root (SRSS) mode combinations for the 9-storey RC frame
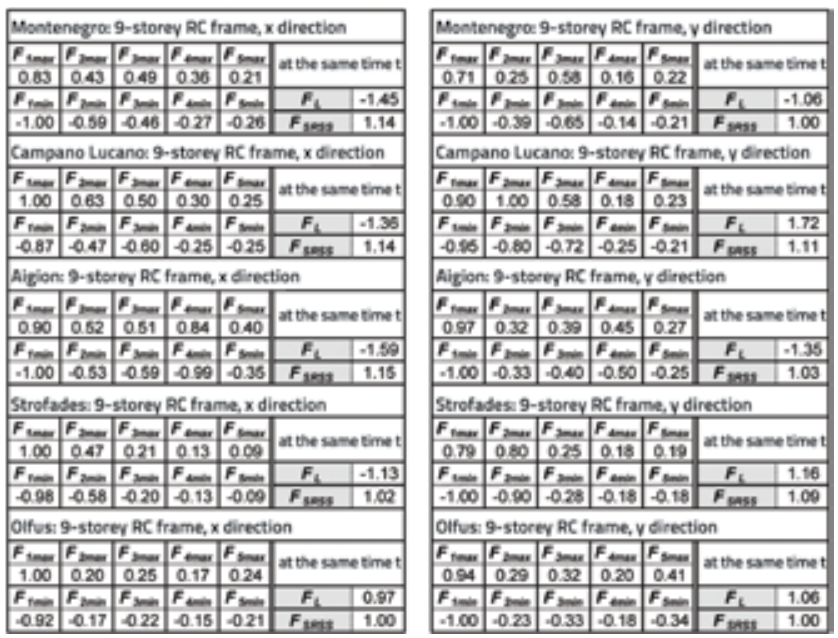

Table 16. Linear (L) and root (SRSS) combination of nonlinear model for the 9-storey RC frame

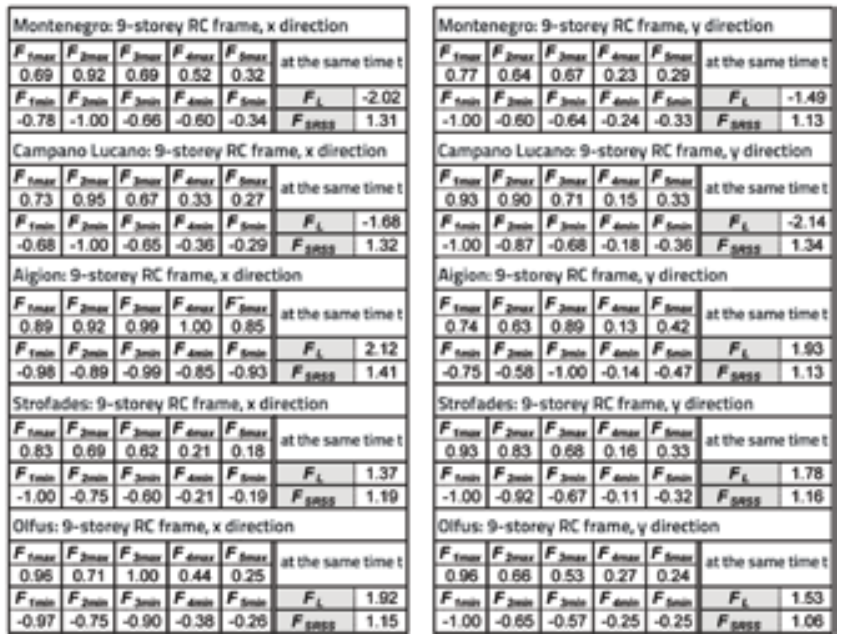

The functions belonging to the figure are defined by the following analytical form:

$$
\begin{aligned}
& f_{s 1}=A\left(1-e^{-\frac{u-B}{C}}\right)+D \\
& f_{s 2}=-A\left(1-e^{\frac{u-B}{C}}\right)+D \\
& f_{s 3}=\frac{A}{C}(u-B)+D
\end{aligned}
$$

The function $f_{S 1}$ corresponds to the bearing capacity curve for an individual mode. It is used to define coefficients $A$ and $C$ in expression (6). The function $f_{s 3}$ is linear and its inclination corresponds to the initial stiffness of the SDOF. Coefficients $B$ and $D$ are calculated in every time step and are used to define the translation of functions $f_{S 1}$ and $f_{S 2}$ along the axis $u$ and $f_{s}$ for coefficients $B$ and $D$, respectively.

Analysis results for nonlinear SDOF for the directions $x$ and $y$, given in Table 15, show simultaneously the least favourable 
combination of the linear superposition of modes $F_{\iota}$, and the least favourable root combination of modes $F_{\text {SRSS }}$

A similar procedure was conducted for the analysis of the 9-storey linear RC space frame from example 2, and the analysis results are given in Table 16.

Dynamic response results for the nonlinear system, as given in tables 15 and 16, show that the linear mode combination $F_{L}$ is in all examples much more unfavourable than the root combination of the sum of the squares $F_{\text {SRSS }}$.

\section{Conclusion}

The paper presents the procedure for determining the target acceleration, defined as the smallest base acceleration leading to the limit state of bearing capacity of a structure using the multimodal pushover approach, which represents the lowest seismic resistance. The procedure is based on the repeated nonlinear analysis of the structure by multimodal pushover method and by repeated search for the target acceleration.

The following conclusions can be made based on results obtained on concrete examples:

- The influence of higher modes, the second and third modes in particular, is very significant.

- The target or the least acceleration of the base does not necessarily cause the lowest horizontal failure forces in the cross section at the base of the calculation model. At that, the target acceleration is always lower than the limit acceleration of each mode taken separately.

- It has been demonstrated that the linear (L) combination of modes is more critical due to smaller target acceleration when compared to such acceleration for the root (SRSS) combination of modes.
- The general failure vector belonging to target acceleration differs significantly by form from the form of load of the first vector, but also from the form of load with constant acceleration along the height of the structure, as given in EN 1998.

- The frequency of occurrence of linear combination and root combination of modes, tested on a concrete series of seismic records, on both linear and nonlinear levels, confirms that the linear combination is more probable that the root combination of the sum of the squares.

- The multimodal pushover method a priori starts from the assumption that all relevant modes are actually activated in case of a real-life seismic action.

- Regardless of the method by which modes are combined, the practical use of the multimodal approach shows that the seismic resistance or reliability of the studied RC frame structures is lower than that based on the target displacement criterion as per EN 1998 (Annex B).

- The inclusion of higher modes in examples presented in the paper regularly and significantly reduces the limit peak ground acceleration and this by more than two times in some situations, which is significantly less favourable than the request for reserve in the bearing capacity curve of $150 \%$ as compared to the typical target displacement of the top of the structure.

\section{Acknowledgement}

This research was supported by the Ministry of Science, Education and Sport of the Republic of Croatia (research project: "Modelling limit bearing capacity and stability of structures at considerable displacements", No.: 0830831541-1545). The authors express their gratitude for this support.

\section{REFERENCES}

[1] European Committee for Standardization (CEN): EN 1998-1. Eurocode 8: Design of Structures for earthquake resistance Part 1: General rules, seismic actions and rules for buildings, Brussels, Belgium, 2004.

[2] ATC, Seismic evaluation and retrofit of concrete buildings, ATC40 Report, Applied Technology Council, Redwood City, California, 1996.

[3] ATC, Improvement of nonlinear static seismic analysis procedures, FEMA 440 Report, Applied Technology Council, Redwood City, California, 2005.

[4] Saiidi, M. \& Sozen, M.A.: Simple Nonlinear Seismic Analysis of R/C Structures, Journal of the Structural Division, Vol. 107, No. 5 , pp. 937-953, 1981.

[5] Fajfar, P. \& Fischinger, M.: Non-linear seismic analysis of RC buildings: Implications of a case study, European Earthquake Engineering, Vol. 1, pp. 31-43, 1987.
[6] Fajfar, P. \& Gašperšič, P.: The N2 method for the seismic damage analysis for RC buildings, Earthquake Engineering \& Structural Dynamics, Vol. 25, pp. 23-67, 1996.

[7] Fajfar, P.: A Nonlinear Analysis Method for Performance Based Seismic Design, Earthquake Spectra, Vol. 16, No.3, pp. 573-592, 2000.

[8] Lagaros, N.D. \& Fragiadakis, M.: Evaluation of ASCE-41, ATC-40 and N2 static pushover methods based on optimally designed buildings, Soil Dynamics and Earthquake Engineering, Vol. 31, pp. 77-90, 2011.

[9] Chopra, A.K. \& Goel, R.K.: A modal pushover analysis procedures for estimating seismic demands for buildings, Earthquake Engineering \& Structural Dynamics, Vol. 31, No. 3, pp. 561-582, 2002.

[10] Jiang, Y., Li, G. \& Yang, D.: A modified approach of energy balance concept based multimode pushover analysis to estimate seismic demands for buildings, Engineering Structures, Vol. 32, No. 5, pp. 1272-1283, 2010. 
[11] Sasaki, K.K., Freeman, S.A. \& Paret, T.F.: Multi-mode pushover procedure (MMP) - a method to identify the effects of higher modes in a pushover analysis, Proceedings of 6th U.S. National Conference on Earthquake Engineering, Seattle (Washington), 1998.

[12] Kalkan, E. \& Kunnath, S.K.: Assessment of current nonlinear static procedures for seismic evaluation of buildings, Engineering Structures, Vol. 29, pp. 305-316, 2007.

[13] Chopra, A.K., Goel, R.K. \& Chintanapakdee, C.: Evaluation of a modified MPA procedure assuming higher modes as elastic to estimate seismic demands, Earthquake Spectra, Vol. 20, No. 3, pp. 757-778, 2004.

[14] Goel, R.K. \& Chopra, A.K.: Role of higher-'mode" pushover analyses in seismic analysis of buildings, Earthquake Spectra, Vol. 21, No. 4, pp. 1027-1041, 2005.

[15] Shakeri, K. \& Mohebbi, M.: Single-run modal pushover procedure based on the modal shear and moment in the stories, Proceedings of 14th European Conference on Earthquake Engineering, Ohrid, Republic of Macedonia, pp. 6199-6207, 2010.
[16] Trogrlić, B. \& Mihanović, A.: The comparative body model in material and geometric nonlinear analysis of space R/C frames, Engineering Computations, Vol. 25, No. 2, pp. 155-171, 2008.

[17] Trogrlić, B., Mihanović, A. \& Nikolić, Ž.: Modified Modal Pushover Analysis of RC Frames, fib Symposium Prague 2011, Concrete engineering for excellence and efficiency, Proceedings, Publisher: Czech Concrete Society (CBS) / Czech fib National Member Group, Vol. 2, pp. 95-98, 2011.

[18] European strong-motion database, http://www.isesd.hi.is/ ESD_Local/frameset.htm, 04.04.2012.

[19] Chopra, A.K.: Dynamics of structures: Theory and Applications to Earthquake Engineering, University of California at Berkeley, Third Edition, Prentice Hall, 2007. 